\title{
CASE REPORT ON CUBITUS VARUS DEFORMITY AS A COMPLICATION OF UNITED MEDIAL CONDYLE OF HUMERUS FRACTURE- A RARE FRACTURE IN CHILDREN
}

\author{
Naba Pallab Chetia1, Aritra Bidyananda², Saurav Patowary³
}

${ }_{1}^{1}$ Assistant Professor, Department of Orthopaedics, Assam Medical College \& Hospital, Dibrugarh, Assam.

2 Postgraduate Trainee, Department of Orthopaedics, Assam Medical College \& Hospital, Dibrugarh, Assam.

3Postgraduate Trainee, Department of Orthopaedics, Assam Medical College \& Hospital, Dibrugarh, Assam.

HOW TO CITE THIS ARTICLE: Chetia NP, Bidyananda A, Patowary S. Case report on cubitus varus deformity as a complication of united medial condyle of humerus fracture- A rare fracture in children. J. Evolution Med. Dent. Sci. 2017;6(94):6912-6915, DOI: $10.14260 /$ jemds/2017/1498

\section{PRESENTATION OF CASE}

A 9-year-old boy was brought to our hospital with deformity and inability to fully flex his left elbow in February 2017. This occurred following injury to this elbow on 10/12/2013 due to fall on outstretched hand. As per documents presently available with him, his injury was diagnosed as fracture of medial condyle of left humerus at another tertiary care teaching hospital. (Figure 1). He was treated by closed reduction and percutaneous internal fixation with two $k$ wires inserted from medial side followed by above elbow POP slab. (Figure 2a, 2b). POP slab and $k$ wires were removed after four weeks and the patient was put on physiotherapy home programme. However, the patient did not continue clinicoradiological followup at that hospital in subsequent period of time.

He had no pain or tenderness or swelling on presentation to us. There was cubitus varus deformity of left elbow associated with internal rotation of the left forearm. (Figure 3). Medial supracondylar ridge was thickened. The relationships of three bony points of tip of the olecranon, medial \& lateral epicondyle were altered. Elbow range of motion was 0-0-100. (Figure 4). There was no limb length discrepancy \& distal neurovascular status was intact. ROM of ipsilateral shoulder and forearm were within normal limits.

AP and lateral view of $x$-rays of elbows of both sides were done for comparison. The medial condyle of humerus fracture had united. But the medial condyle was ill developed and there was medial subluxation of radius and ulna. Baumann's angle decreased compared to other side. (Figure $5 \mathrm{a}, 5 \mathrm{~b}$ ). After thorough counselling of patient and parents, under general anaesthesia, supracondylar lateral close wedge osteotomy and internal fixation with two $\mathrm{k}$ wires was done through lateral approach. (Figure 6a). The k-wires were inserted parallel to each other from lateral side under c-arm fluoroscopy guidance and above elbow POP cast was applied. (Figure 6a, 6b). Patient was clinicoradiologically followed up regularly at two weeks interval. At six weeks, POP cast and $\mathrm{k}$ wires were removed (Figure $7 \mathrm{a}, 7 \mathrm{~b}$ ) and the patient was put on ROM and strengthening exercises under supervision of physiotherapists. (Figure 8, 9a, 9b, 9c, 9d).

'Financial or Other Competing Interest': None.

Submission 30-10-2017, Peer Review 26-11-2017,

Acceptance 01-12-2017, Published 18-12-2017.

Corresponding Author:

Dr. Aritra Bidyananda,

Department of Orthopaedics,

Assam Medical College \& Hospital,

Dibrugarh-786002,

Assam.

E-mail: aritra.bidyananda@gmail.com

DOI: $10.14260 /$ jemds $/ 2017 / 1498$

\section{(c) (1) $\$($}

\section{DIFFERENTIAL DIAGNOSIS}

In children, cubitus varus deformity of the elbow following trauma can commonly result as a sequel of misdiagnosed, untreated or inadequately treated supracondylar, lateral condyle, medial condyle and physeal injury of distal humerus.

\section{CLINICAL DIAGNOSIS}

Clinically, it was a case of left-sided cubitus varus deformity with internal rotation of left forearm with posteromedial subluxation and restricted movement of left elbow in a 9year-old boy following closed reduction and percutaneous $\mathrm{k}$ wire fixation for medial condyle of humerus fracture more than 3 years ago.

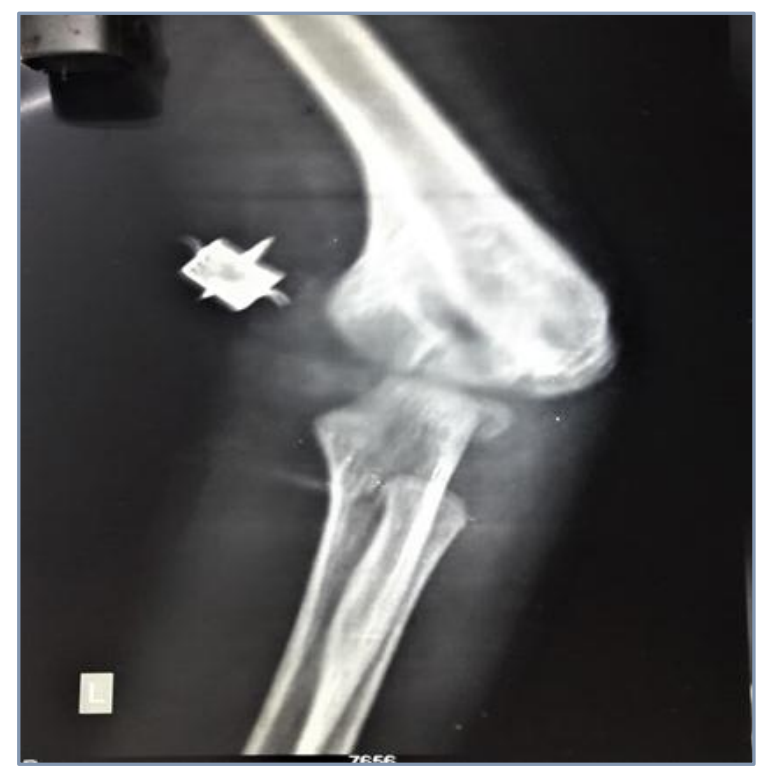

Figure 1. Fracture of Medial Condyle of Humerus in Preoperative X-ray

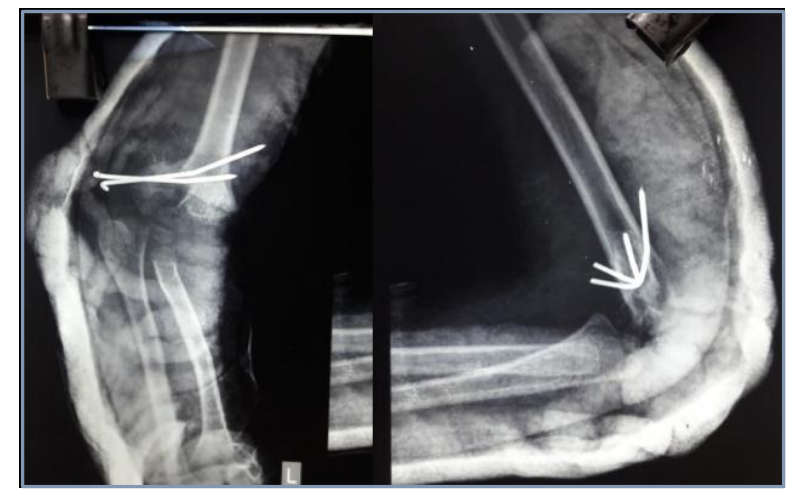

Figure 2a, b. Post-operative X-ray (AP \& Lateral) of Internal Fixation of Fracture Medial Condyle 


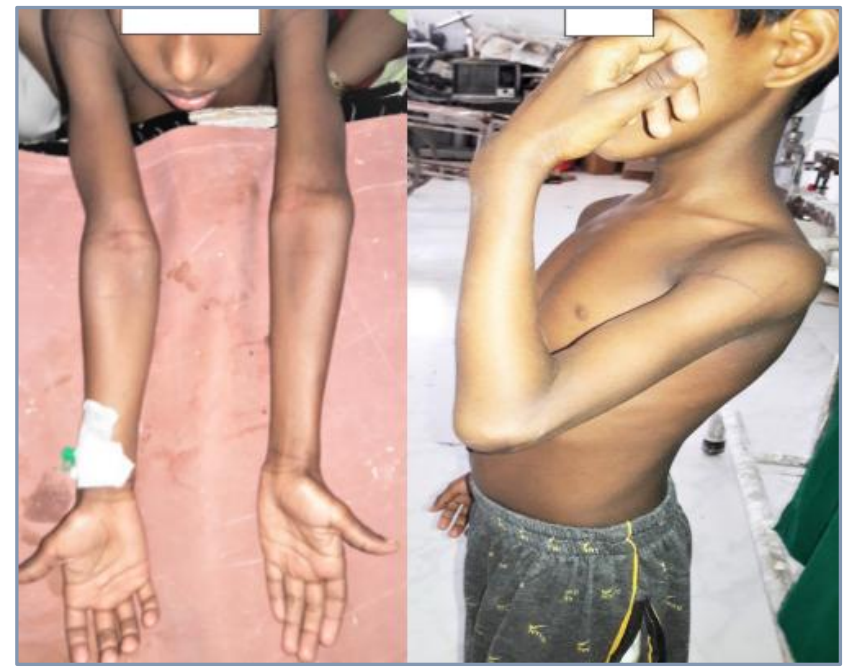

Figure 3a, b. Pre-operative Clinical Photograph showing Left-sided Cubitus Varus with

Internal Rotation of Forearm \& Restricted Flexion of Left Elbow Joint

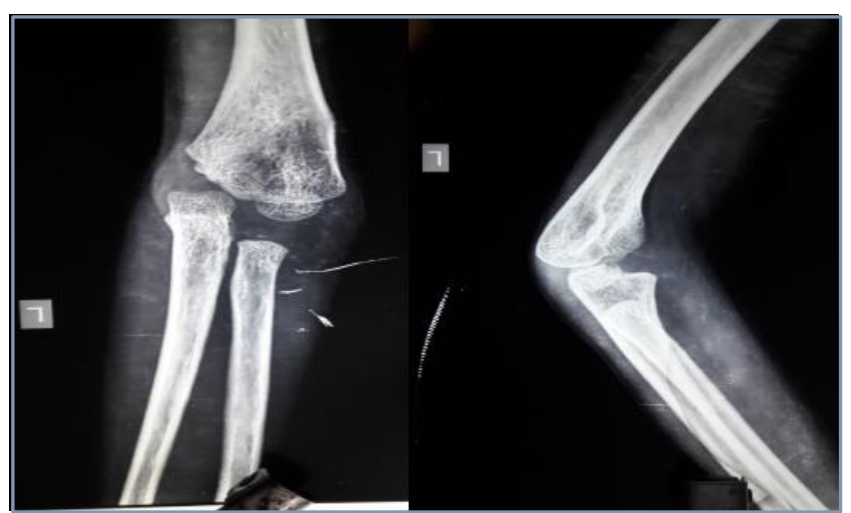

Figure 5a, b. Preoperative X-ray (AP \& Lateral) showing III-developed Medial Condyle

of Humerus with Decreased Baumann's Angle \& Posteromedial Subluxation of Left Elbow Joint

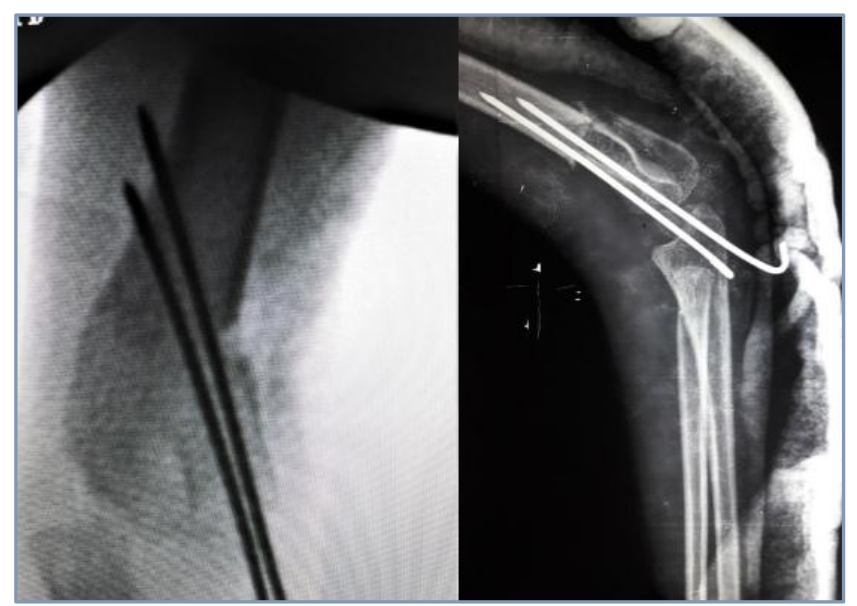

Figure 6a, b. C-arm Picture and Immediate Post-operative $X$-ray Following Supracondylar Osteotomy of Left Humerus \& Internal Fixation with $K$ wire

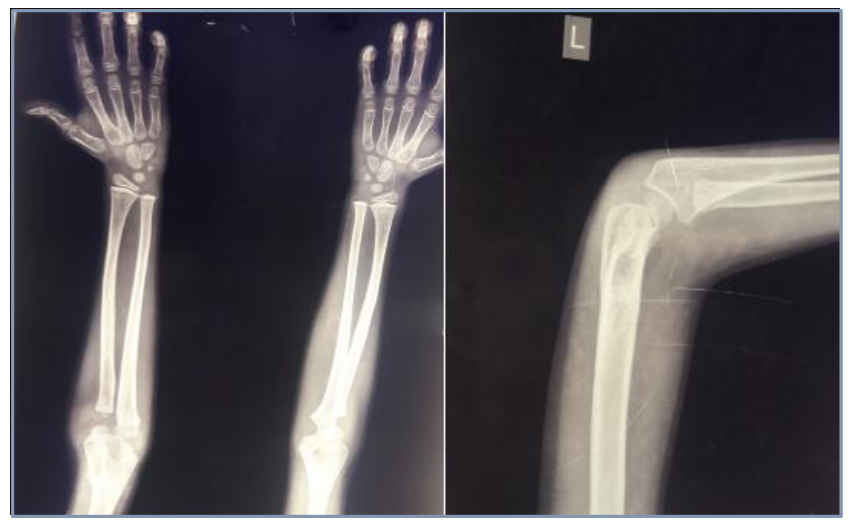

Figure 7a, b. At 4 months Followup-Correction of Cubitus Varus Deformity Following Union of Osteotomy \& K wire Removal Compared to Contralateral Side

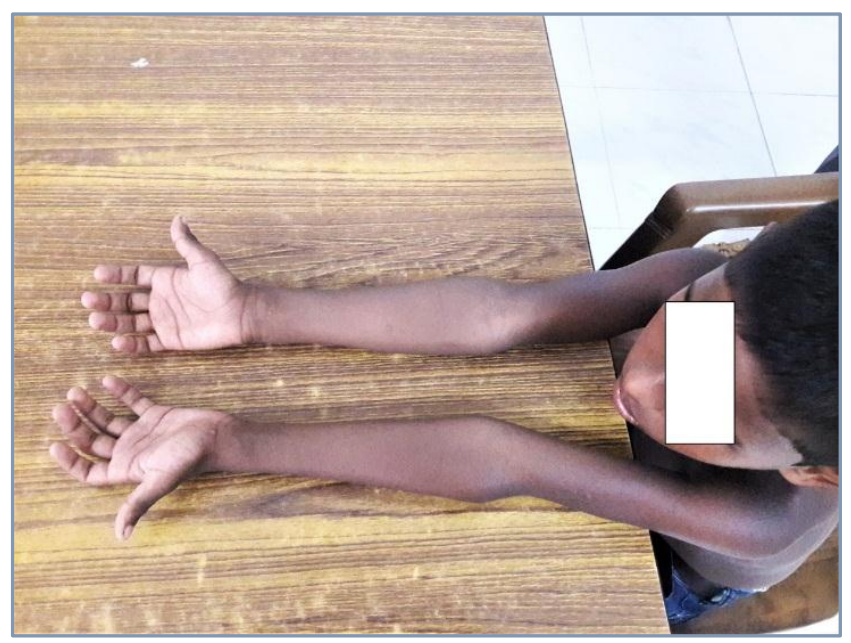

Figure 8. At 4 months Followup- Clinical Correction of Cubitus Varus and Internal Rotation Deformity

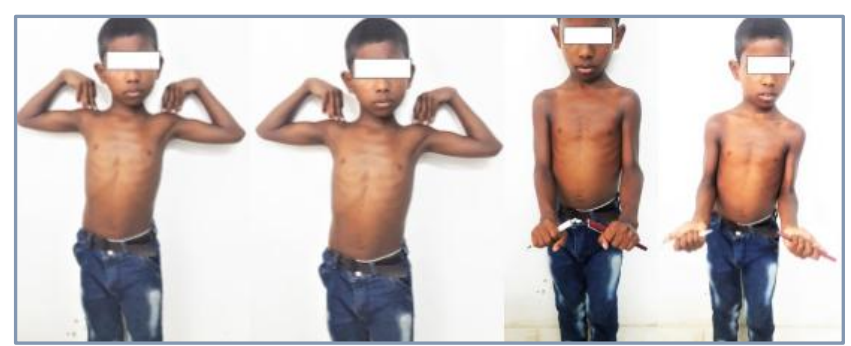

Figure 9a, b, c, d-At 4 months Followup Clinical Photograph

showing Normal ROM of Left Forearm and Elbow

\section{PATHOLOGICAL DISCUSSION}

Fractures of the medial condyle of humerus behave as the mirror image of lateral condyle fractures.[1] These fractures are rare in skeletally immature children, accounting for less than $1 \%$ of fractures involving the distal humerus.[2] Many of the large series of elbow fractures in the literature and early fracture texts do not mention fractures of medial condyle of humerus in children as a separate entity. Blount[3] described only one such fracture in his classic text. In Faysse and Marion's[4] review of more than 2, 000 fractures of the distal humerus in children, only 10 fractures involved the medial condyle. 
Most series ${ }^{[4],[5]}$ show medial condylar fractures occurring somewhat later than lateral condylar fractures. A review of 38 patients in nine series,[6],[7],[8],[9] in which the specific ages were given showed that 37 patients were in the age range of 8 to 14 years. Thus, this fracture seems to occur most often after the ossification centres of the medial condylar epiphysis begin to appear. However, a medial condylar fracture can occur as early as 6 months of age, before any ossification of the distal humerus has appeared.[10], [11] Although falling directly on the point of the flexed elbow is implicated as mechanism of injury,[7],[10],[12],[13] yet in some series,[14],[15],,[16] many patients sustained this injury when they fell on their outstretched arms implicating that this is an avulsion injury caused by a valgus strain at the elbow.

Clinically and on radiographs, a fracture of the medial condylar physis is most often confused with a fracture of the medial epicondyle.[17] A high index of suspicion is necessary to avoid missing a displaced, intra-articular medial condyle fracture in the young. In both types, swelling is concentrated medially, and there may be valgus instability of the elbow joint. In a true medial condyle fracture; however, there is varus instability in addition as well. [1]

In older children with a large metaphyseal fragment, involvement of the entire condyle is usually obvious on radiographs. However, in younger children, in whom only the epicondyle is ossified, fracture of the medial condylar physis may be erroneously diagnosed as an isolated fracture of the medial epicondyle.[8],[9],[15]

Whereas medial epicondyle fractures are often associated with elbow dislocations, usually posterolateral but with medial condylar physeal fractures, the elbow tends to subluxate posteromedially[8] because of the loss of trochlear stability.

Any metaphyseal ossification with the epicondylar fragment suggests the presence of an intra-articular fracture of the medial condyle. A positive fat pad sign indicates that a fracture of the medial condyle is likely.[12],[18] Isolated fractures of the medial epicondyle are extra-articular and usually do not have positive fat pad signs. When the diagnosis is a real possibility, especially in a child with no ossification of the trochlea, examination with anaesthesia, arthrography, and/or MRI is required.

Kilfoyle[19] described three fracture displacement patterns that can be helpful in determining appropriate treatment. In type I, the fracture line in the medial condylar metaphysis extends down to the physis. In type II, the fracture line extends into the medial condylar physis. The intra-articular portion, as it is in precocious cartilage, is often not recognised. The medial condylar fragment usually remains undisplaced. In type III, the condylar fragment is both rotated and displaced. The metaphyseal fragment includes the intact medial epicondyle along with the common flexor origin of the muscles of the forearm. These flexor muscles cause the loosened fragment to rotate so that the fracture surface is facing anteriorly and medially and the articular surface is facing posteriorly and laterally.[6],[7] Rotation of the fragment is especially accentuated when the elbow is extended.

The major complication is failure to make the proper diagnosis. This is especially true in younger children, in whom a medial condylar fracture can be confused with a displaced fracture of the medial epicondyle. [1] Leet et al[20] reported complications after $33 \%$ of twenty one medial condylar fractures, including osteonecrosis of the trochlea, non-union and loss of reduction. Untreated displaced fractures usually result in non-union with cubitus varus deformity.[15], [21] These patients are at high risk for loss of motion, function, pain, and eventual arthrosis. Delayed union has been reported in patients treated with insecure fixation or simply placed in a cast.[19] Some disturbance of the vascular supply to the medial condylar fragment may occur during open reduction and internal fixation or at the time of initial injury. Several investigators have reported subsequent avascular changes in the medial crista of the trochlea. $[5],[15],[19]$ Both cubitus varus and valgus deformities have been reported in patients whose fractures united uneventfully. The valgus deformity appears to be caused by secondary stimulation or overgrowth of the medial condylar fragment. Some simple stimulation of the medial epicondyle's prominence may also produce the false appearance of a cubitus valgus deformity. Cubitus varus appears to result from decreased growth of the trochlea, possibly caused by a vascular insult. [1]

\section{DISCUSSION OF MANAGEMENT}

In types I and II fractures, enough residual internal stability is usually present to allow the fracture to be simply immobilised in a cast or posterior splint. [4],[5],[10],[22],[23] However, union may be slow in them. In fractures treated promptly, results have been satisfactory.[10] Because there is usually more displacement in older children, the results of non-operative treatment in this age group are not as satisfactory as those in younger children, who tend to have relatively nondisplaced fractures. ${ }^{[10]}$

For displaced fractures, open reduction with internal fixation is the most often used treatment method. [5],,[10],,[14],,[15],[19][24].The fracture fragment can be approached by a posteromedial incision that allows good exposure of both the fracture site and the ulnar nerve. Fixation is easily achieved with smooth K-wires or with screws in older adolescents. Two wires are necessary because of the sagittal rotation forces exerted on the fracture fragment by the common flexor muscles. El Ghawabi[16] reported frequent delayed union and non-union in fractures that were not rigidly stabilised.

The cubitus varus deformity is distinctive on x-ray as evident by decreased Baumann's angle on AP view. Osteotomy is the only way to correct a cubitus varus deformity with a high probability of success. Cubitus varus deformity in addition to cosmetic appearance, result in elbow discomfort, pain, tardy posterolateral rotational instability, increased risk of lateral condyle fractures and late ulnar nerve palsies which may be indications for correction of deformity with a supracondylar humeral osteotomy.[25],[26],[27],[28],[29],[30],[31],[32],[33]

\section{FINAL DIAGNOSIS}

Clinicoradiologically, it was a case of left-sided cubitus varus deformity with internal rotation of left forearm with posteromedial subluxation and restricted movement of left elbow in a 9-year-old boy due to united ill-developed medial condyle of humerus following its treatment by closed 
reduction and percutaneous $\mathrm{k}$-wire fixation more than 3 years ago.

\section{REFERENCES}

[1] Flynn JM, Skaggs DL, Waters PM. Rockwood and Wilkins' Fractures in children. 8th edn. Wolters Kluwer Health 2015.

[2] Ingersoll RE. Fractures of the humeral condyles in children. Clin Orthop Relat Res 1965;41:32-42.

[3] Blount WP. Fractures in Children. Baltimore: Williams and Wilkins Co., (London: Bailliere, Tindall \& Cox) 1955;43(177): p. 110.

[4] Faysse R, Marion J. Fractures du condyle interne. Rev Chir Orthop 1962;48:473-7.

[5] Papavasiliou V, Nenopoulos S, Venturis T. Fractures of the medial condyle of the humerus in childhood. J Pediatr Orthop 1987;7(4):421-3.

[6] Churst APC. An anatomical and surgical study of fractures of the lower end of the humerus. Philadelphia: Lea \& Febiger 1910.

[7] Chacha PB. Fractures of the medial condyle of the humerus with rotational displacement. J Bone Joint Surg Am 1970;52:1453-8.

[8] Cothay DM. Injury to the lower medial epiphysis of the humerus before development of the ossific centre. Report of a case. J Bone Joint Surg Br 1967;49(4):7667.

[9] Fahey JJ, O'Brien ET. Fracture-separation of the medial humeral condyle in a child confused with fracture of the medial epicondyle. J Bone Joint Surg Am 1971;53(6):1102-4.

[10] Bensahel H, Csukonyi Z, Badelon O, et al. Fractures of the medial condyle of the humerus in children. J Pediatr Orthop 1986;6(4):430-3.

[11] Brock HD, Casteleya PP, Opdecam P. Fracture of the medial humeral condyle: report of a case in an infant. J Bone Joint Surg Am 1987;69(9):1442-4.

[12] Harrison RB, Keats TE, Frankel CJ, et al. Radiographic clues to fractures of the unossified medial humeral condyle in young children. Skeletal Radiol 1984;11(3):209-12.

[13] Potter CM. Fracture-dislocation of the trochlea. J Bone Joint Surg Br 1954;36-B(2):250-3.

[14] Case SL, Hennrikus WL. Surgical treatment of displaced medial epicondyle fractures in adolescent athletes. Am J Sports Med 1997;25(5):682-6.

[15] Fowles JV, Kassab MT. Displaced fractures of the medial humeral condyle in children. J Bone Joint Surg Am 1980;62(7):1159-63.

[16] Ghawabi MH. Fracture of the medial condyle of the humerus. J Bone Joint Surg Am 1975;57(5):677-80.

[17] Lee HH, Shen HC, Chang JH, et al. Operative treatment of displaced medial epicondyle fractures in children and adolescents. J Shoulder Elbow Surg 2005;14(2):178-85.

[18] Skaggs DL, Mirzayan R. The posterior fat pad sign in association with occult fracture of the elbow in children. J Bone Joint Surg Am 1999;81(10):1429-33.
[19] Kilfoyle RM. Fractures of the medial condyle and epicondyle of the elbow in children. Clin Orthop Relat Res 1965;41:43-50.

[20] Leet AI Young C, Hoffer MM. Medial condyle fractures of the humerus in children. J Pediatr Orthop 2002;22(1):2-7.

[21] Varma BP, Srivastava TP. Fractures of the medial condyle of the humerus in children: a report of four cases including the late sequelae. Injury 1972;4(2):171-4.

[22] Glotzbecker MP, Bae DS, Links AC, et al. Fishtail deformity of the distal humerus: a report of 15 cases. J Pediatr Orthop 2013;33(6):592-7.

[23] Kim HT, Song MB, Conjares JN, et al. Trochlear deformity occurring after distal humeral fractures: magnetic resonance imaging and its natural progression. J Pediatr Orthop 2002;22(2):188-93.

[24] Pimpalnerkar AL, Balasubramaniam G, Young SK, et al. Type four fracture of the medial epicondyle: a true indication for surgical intervention. Injury 1998;29(10):751-6.

[25] Abe M, Ishizu T, Morikawa J. Posterolateral rotatory instability of the elbow after posttraumatic cubitus varus. J Shoulder Elbow Surg 1997;6(4):405-9.

[26] Abe M, Ishizu T, Shirai H, et al. Tardy ulnar nerve palsy caused by cubitus varus deformity. J Hand Surg Am 1995;20(1):5-9.

[27] Beuerlein MJ, Reid JT, Schemitsch EH, et al. Effect of distal humeral varus deformity on strain in the lateral ulnar collateral ligament and ulnohumeral joint stability. J Bone Joint Surg Am 2004;86-A(10):223542.

[28] McKee M. Progressive cubitus varus due to a bony physeal bar in a 4-year-old girl following a supracondylar fracture. A case report. J Orthop Trauma 2006;20(5):372.

[29] Davids JR, Maguire MF, Mubarak SJ, et al. Lateral condylar fracture of the humerus following posttraumatic cubitus varus. J Pediatr Orthop 1994;14(4):466-70.

[30] O'Driscoll SW, Spinner RJ, McKee MD, et al. Tardy posterolateral rotatory instability of the elbow due to cubitus varus. J Bone Joint Surg Am 2001;83A(9):1358-69.

[31] Spinner RJ, O'Driscoll SW, Davids JR, et al. Cubitus varus associated with dislocation of both the medial portion of the triceps and the ulnar nerve. J Hand Surg Am 1999;24(4):718-26.

[32] Mitsunari A, Muneshige H, Ikuta $Y$, et al. Internal rotation deformity and tardy ulnar nerve palsy after supracondylar humeral fracture. J Shoulder Elbow Surg 1995;4(1 Pt 1):23-9.

[33] Uchida Y, Sugioka Y. Ulnar nerve palsy after supracondylar humerus fracture. Acta Orthop Scand 1990;61(2):118-9. 